\title{
MonitoRE: Um Arcabouço de Sistema para Monitoramento de Tarefas na Robótica Educacional
}

\author{
Marcel L. Rios' ${ }^{1}$, José F. Magalhães Netto ${ }^{2}$ \\ ${ }^{1}$ Instituto Federal de Rondônia (IFRO) - Campus Zona Norte \\ Porto Velho - RO - Brasil \\ ${ }^{2}$ Universidade Federal do Amazonas (UFAM) \\ Porto Velho - RO - Brasil \\ marcel.rioseifro.edu.br, jnetto@ufam.edu.br
}

\begin{abstract}
A frequent concern among students and teachers working with educational robotics is on the results obtained through practical activities. Currently, educational institutions and robotics competitions lack mechanisms that can evaluate the performance of mobile robots programmed by students. In this work, we present a technological solution that uses computational vision to evaluate the movements of the mobile robot, comparing with the established criteria for the challenge. The experiments showed that the method adopted is effective in environments with constant illumination. And the questionnaires pointed out that this solution can motivate teachers and students.
\end{abstract}

Resumo. Uma preocupação frequente entre estudantes e professores que trabalham com robótica educacional é sobre os resultados obtidos por meio de atividades práticas. Atualmente, as instituições de ensino e as competições de robótica educacional carecem de mecanismos que possam avaliar o desempenho de robôs móveis programados pelos alunos. Neste trabalho, apresentamos uma solução tecnológica que utiliza visão computacional para avaliar os movimentos do robô móvel, comparando com os critérios estabelecidos para o desafio. Os experimentos mostraram que o método adotado é eficaz em ambientes com iluminação constante. E os questionários apontaram que esta solução pode motivar professores e alunos.

\section{Introdução}

A Robótica Educacional é uma dessas tecnologias que proporcionam ao professor e seus alunos uma experiência de estudo inovadora em diversas áreas do conhecimento [Alimisis, 2009], [Hamner et al. 2016]. Além de motivar os alunos e proporcionar trabalho em equipe, a robótica permite o desenvolvimento da criatividade através do construcionismo, que vão desde montagem de peças e engrenagens até a programação das funcionalidades de um robô [El-howayek, 2016], [Khanlari, 2016].

A robótica dentro do ambiente escolar oferece, tanto para o professor quanto para o aluno, oportunidades de experimentar novos ambientes de aprendizagem, proporcionando atividades que além de desafiar, tendem a motivar o aluno, uma vez que utiliza da criatividade e lógica do aluno na apresentação de soluções de hardware e software, a partir da resolução de uma situação-problema [Fiorio et al. 2014]. 
VII Congresso Brasileiro de Informática na Educação (CBIE 2018)

Anais do XXIX Simpósio Brasileiro de Informática na Educação (SBIE 2018)

Com os avanços da tecnologia está cada vez mais comum à utilização de laboratórios remotos que possibilitam pessoas geograficamente distantes experimentem robôs, no entanto, essa abordagem também carece de métodos que possam computar e analisar o comportamento robótico [Almeida et al. 2017].

Neste contexto, existem várias maneiras de desenvolver projetos de Robótica Educacional, uma delas é por meio da Robótica Móvel. Um dos grandes desafios da robótica móvel é o problema da navegação autônoma. Nesse cenário, conhecer a localização exata do robô ou estimar sua posição e trajetória é uma tarefa primordial [Martins et al. 2011]. Uma das alternativas consiste na elaboração de ambientes de tarefas que tanto desafiem o conhecimento dos alunos como favoreça a análise da trajetória percorrida pelo robô móvel [Rios et al. 2016].

Desta forma, este trabalho apresenta a configuração de três ambientes de tarefas e uma solução tecnológica, denominada MonitoRE - Sistema de Monitoramento para Robótica Educacional, que utiliza Visão Computacional para avaliar o desempenho do robô móvel em cenários de Robótica Educacional. Os resultados mostraram que a solução apresentada é eficiente e permite auxiliar o processo de ensino-aprendizagem.

Este artigo está organizado da seguinte maneira: a Seção 2 apresenta a descrição do trabalho proposto. A Seção 3 descreve os materiais e métodos utilizados durante o desenvolvimento desta pesquisa. A Seção 4 exibe os resultados e discussões sobre os questionários e testes realizados. Por fim, a Seção 5 apresenta as conclusões do trabalho.

\section{Descrição do Trabalho}

Esta seção descreve a justificativa, o objetivo geral e a metodologia de pesquisa adotada neste trabalho, apresentando os estágios das tarefas desenvolvidas durante o processo de pesquisa científica.

\subsection{Justificativa}

Muitos trabalhos utilizam a robótica educacional para o ensino de programação, porém poucas são as iniciativas que vão além do ensino de programação ou de conteúdos escolares específicos, nesse sentido a robótica pode ser utilizada para estimular outros conteúdos relacionados ao ensino de computação [Oliveira and Araújo, 2016].

Entretanto, ainda é preciso um método sistemático de elaboração e avaliação de práticas pedagógicas utilizando robótica. Em um currículo de cursos técnicos ou de graduação, a construção dessas práticas deve refletir o conteúdo programático envolvido, bem como os conceitos fundamentais que devem ser aprendidos. Consequentemente, há a necessidade de criar meios avaliativos que sejam efetivos e que colaborem para obtenção de resultados fidedignos [Benitti, 2012].

A robótica educativa também conhecida como robótica pedagógica é caracterizada por ambientes de aprendizagem onde o aluno pode montar e programar um robô ou sistema robotizado [Costella et al. 2017]. Estes ambientes devem ser caracterizados e possuir regras que devem nortear a trajetória do robô móvel, porém ainda faltam mecanismos que possam automatizar a avaliação do desempenho robótico durante a realização das tarefas propostas [Rios and Netto, 2016]. 
VII Congresso Brasileiro de Informática na Educação (CBIE 2018)

Anais do XXIX Simpósio Brasileiro de Informática na Educação (SBIE 2018)

Desta forma, neste trabalho foram estabelecidos os ambientes de tarefas, classificados em três níveis de dificuldade, destinados a alunos do ensino médio, caracterizados para permitir que tanto o robô móvel, programado pelo aluno, como o sistema MonitoRE obtenham seus respectivos parâmetros para o processamento.

\subsection{Objetivo Geral}

Este trabalho tem como objetivo desenvolver e avaliar uma solução tecnológica que monitore a trajetória de robôs móveis utilizando técnicas de Visão Computacional com a finalidade de dar apoio ao processo avaliativo sobre ambientes de tarefas no contexto da Robótica Educacional.

\subsection{Metodologia de Pesquisa}

De modo geral, esta pesquisa contemplou uma abordagem quantitativa e qualitativa. $\mathrm{Na}$ abordagem quantitativa foram gerados dados estatísticos sobre a precisão da solução tecnológica ao avaliar a trajetória do robô móvel em um dado ambiente de tarefa. Dentro dessa abordagem, a pesquisa ocorreu de forma experimental e empírica, submetendo o robô móvel e o sistema proposto a situações de tentativa e erro.

$\mathrm{Na}$ abordagem qualitativa foram obtidas as opiniões dos professores e alunos sobre os ambientes de tarefas estabelecidos, bem como, sobre a solução tecnológica apresentada neste trabalho. O procedimento de coleta de dados para a pesquisa de opinião ocorreu por meio de questionários, complementando a pesquisa de [Rios, 2017].

A metodologia de pesquisa deste trabalho foi organizada em quatro fases distintas e complementares, a saber: Concepção, Elaboração, Construção e Consolidação, conforme ilustrado na Tabela 1.

Tabela 1. Fases da Metodologia de Pesquisa.

\begin{tabular}{|c|c|l|}
\hline Fase & Tarefa & \multicolumn{1}{c|}{ Insumo } \\
\hline \multirow{2}{*}{ Concepção } & - Investigação do & - Revisão Sistemática da Literatura - RSL \\
\cline { 3 - 3 } & problema & - Conhecimento do Estado da Arte \\
\hline \multirow{2}{*}{ Elaboração } & \multirow{3}{*}{ - Definir solução } & - Questionários de Pré-Teste \\
\cline { 3 - 3 } & & - Estabelecer Ambientes de Tarefas \\
\cline { 3 - 3 } & & - Especificação da Linguagem de Programação \\
\hline \hline \multirow{2}{*}{ Construção } & \multirow{2}{*}{ - Desenvolver solução } & - Estabelecer Critérios e Parâmetros p/ Sistema \\
\cline { 3 - 3 } & & - Desenvolvimento do Protótipo e da Solução \\
\hline \hline \multirow{2}{*}{ Consolidação } & \multirow{2}{*}{ - Avaliar solução } & - Testar solução \\
\cline { 3 - 3 } & & - Questionários de Pós-Teste \\
\hline
\end{tabular}

Na fase de Concepção, foi realizada uma revisão sistemática sobre avaliação de desempenho robótico em cenários de Robótica Educacional, identificando os trabalhos correlatos com o objetivo de verificar as tecnologias utilizadas e os resultados alcançados. $\mathrm{Na}$ fase de Elaboração foram aplicados os questionários de pré-teste, além de analisar e estabelecer os possíveis ambientes de tarefas e linguagem de programação. $\mathrm{Na}$ fase de Construção, foram estabelecidos os critérios e os parâmetros para cada ambiente de tarefa, os quais foram implementados no sistema MonitoRE. Finalmente, na fase de Consolidação, o protótipo foi testado e, a partir daí, seu funcionamento foi 
VII Congresso Brasileiro de Informática na Educação (CBIE 2018)

Anais do XXIX Simpósio Brasileiro de Informática na Educação (SBIE 2018)

aprimorado. Os experimentos e testes levantaram os dados necessários para a abordagem quantitativa. Em seguida, os questionários de Pós-Teste subsidiaram a abordagem qualitativa, levantando as opiniões dos professores e alunos que tiveram a experiência de utilizar um ambiente robótico monitorado.

\section{Materiais e Métodos}

Esta seção apresenta a arquitetura proposta neste trabalho, explicando a configuração dos ambientes de tarefas (cenários robóticos) e as funcionalidades do sistema MonitoRE.

\subsection{Arquitetura do Sistema}

Basicamente, o sistema conhece as características do ambiente de tarefa (cenário de desafio robótico), utilizando cores e formas para identificar os marcos artificiais existentes no cenário, cujo mesmo determina os critérios de navegabilidade para o robô móvel. A Figura 1 apresenta a visão geral da arquitetura proposta.

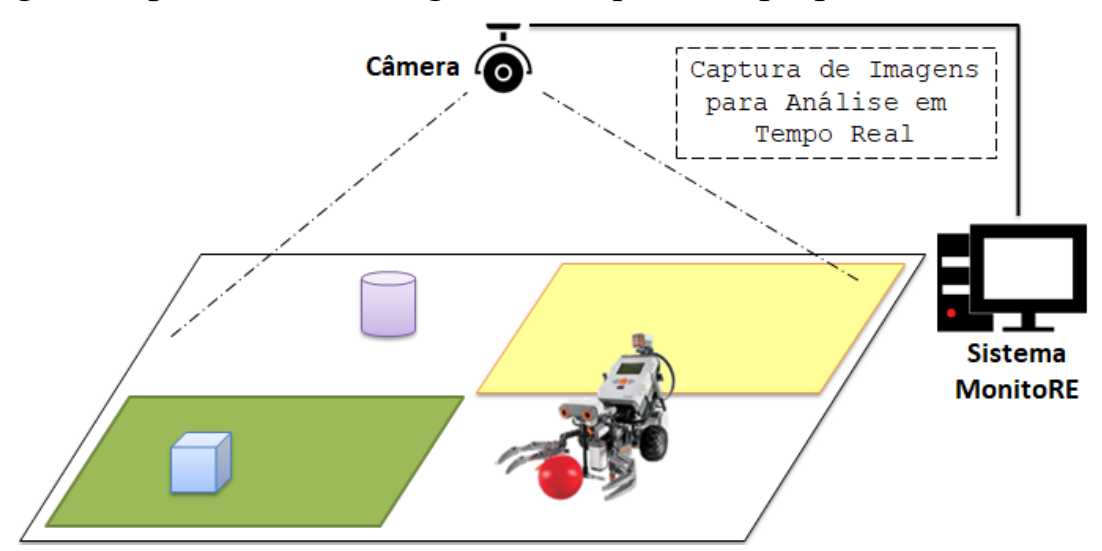

Figura 1. Visão Geral da Arquitetura Proposta - MonitoRE.

Nesta arquitetura o professor deve preparar o ambiente de tarefa em uma sala de aula com iluminação constante, utilizando uma estrutura para colocar a câmera webcam, fixada verticalmente a cerca de $1,50 \mathrm{~cm}$ (um metro e cinquenta centímetros) de altura do ambiente da tarefa. A câmera, conectada ao sistema MonitoRE, faz a captura de imagens (frames) para que o sistema realize o processo de segmentação e detecção de marcos artificiais (características) existentes no ambiente da tarefa, utilizando descritores baseados em cor e forma. A extração desses parâmetros permite ao sistema rastrear a trajetória do robô móvel (programado pelos alunos), comparando com os critérios estabelecidos para a atividade proposta, verificando o desempenho do robô móvel.

O sistema MonitoRE foi desenvolvido com tecnologia web, utilizando HTML e CSS para definição do layout, configuração e organização das páginas do sistema. A construção da parte lógica e processamento de imagens foi desenvolvida na linguagem de programação Python com apoio da biblioteca de visão computacional, OpenCV. 
VII Congresso Brasileiro de Informática na Educação (CBIE 2018)

Anais do XXIX Simpósio Brasileiro de Informática na Educação (SBIE 2018)

\subsection{Ambientes de Tarefas}

Uma das iniciativas deste trabalho foi criar ambientes de tarefas que propiciem a aplicação de métodos avaliativos que sejam efetivos e que colaborem para a apresentação de resultados fidedignos. Além disso, torna-se uma tarefa primordial construir ambientes de tarefas que desafiem o conhecimento dos alunos, bem como, que favoreçam a análise da trajetória do robô móvel em suas missões de navegação.

A Figura 2 apresenta os ambientes de tarefa propostos neste trabalho (medindo 120x90 cm) os quais são completamente observáveis e determinísticos, classificados em três níveis, destinados a alunos do ensino médio, inspirados de [Rios and Netto, 2016] e adaptado de [Silva, 2015].
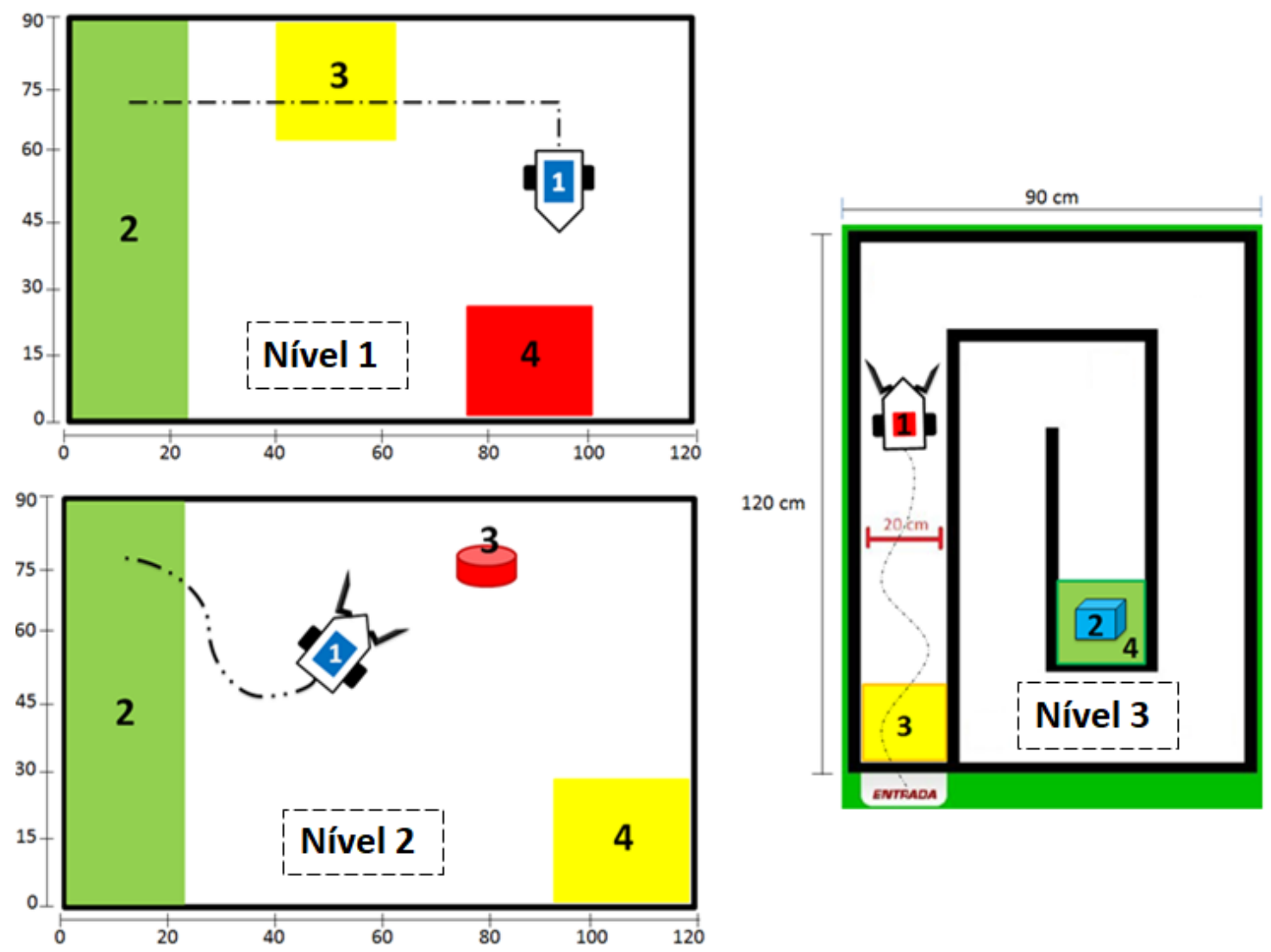

Figura 2. Proposição dos Ambientes de Tarefas.

O ambiente de tarefa para o Nível 01, indicado para alunos que estão iniciando, possui marcadores (check points - identificados na imagem pelos números 2,3 e 4) por onde o robô móvel deve passar. O ambiente de tarefa para o Nível 02, indicado para alunos que estão na fase intermediária, possui um objeto (indicado pelo número 3 ) que precisa ser resgatado pelo robô e colocado em um local seguro (indicado pelo número 4). O ambiente de tarefa para o Nível 03, indicado para alunos com conhecimentos mais avançados em robótica, consiste na "viagem ao centro da terra" onde o robô móvel deve seguir o caminho para o centro da espiral com o objetivo de capturar o cubo (identificado pelo número 2) e retornar pelo no mesmo caminho até a posição inicial (identificado pelo número 3 ). 
VII Congresso Brasileiro de Informática na Educação (CBIE 2018)

Anais do XXIX Simpósio Brasileiro de Informática na Educação (SBIE 2018)

\subsection{Funcionalidades do Sistema MonitoRE}

O MonitoRE é um sistema que proporciona ao professor o monitoramento dos ambientes de tarefas de Robótica Educacional, avaliando o desempenho dos robôs móveis programados pelos alunos. O foco principal do sistema consiste no rastreamento da trajetória percorrida pelo robô móvel, conforme demonstra a Figura 3, o sistema verifica se o robô está cumprindo com o desafio proposto, fazendo notificações em tempo real.

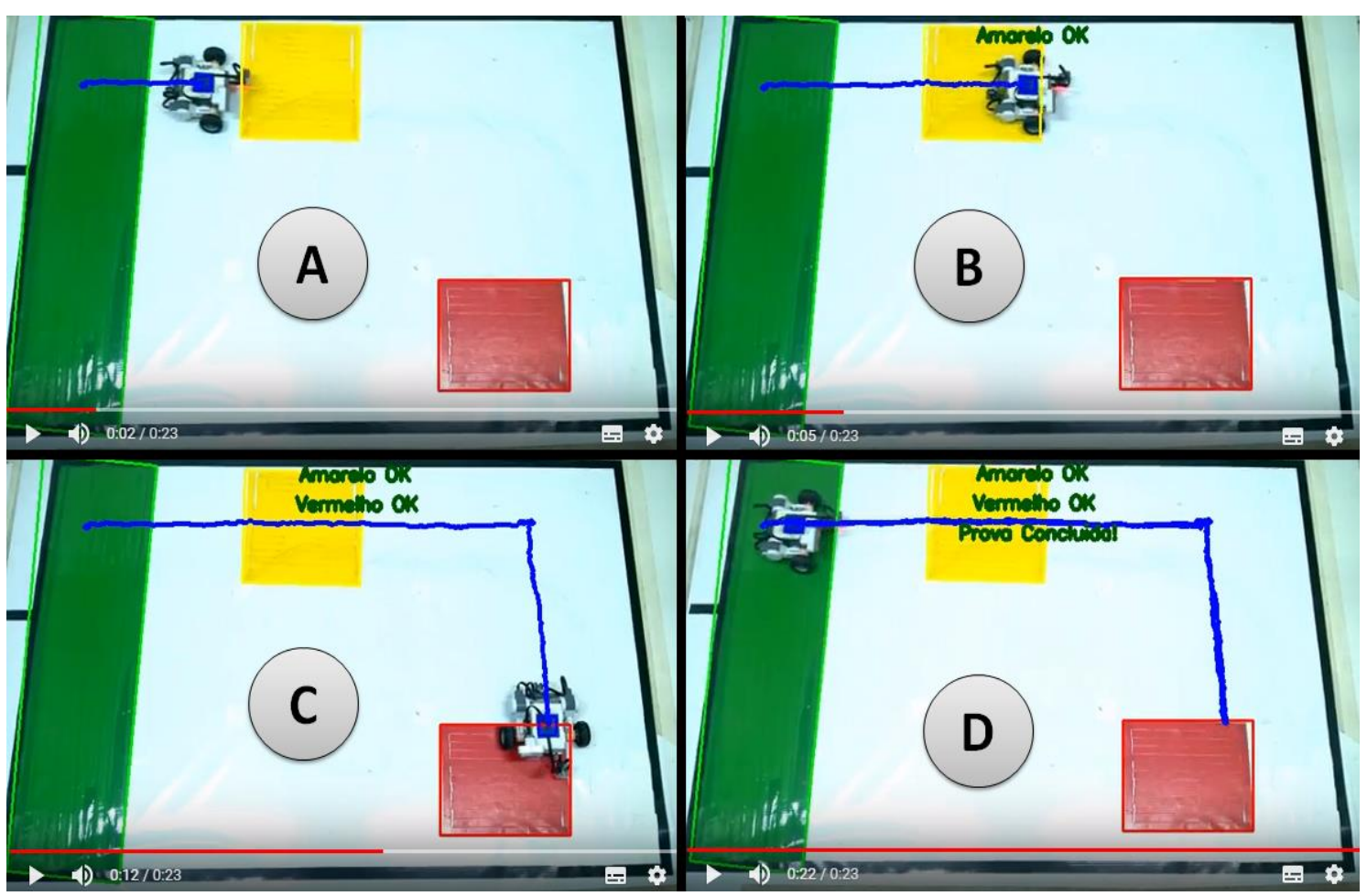

Figura 3. Reconhecimento de Ações no Ambiente de Tarefa de Nível 1.

É possível observar na Figura 3 que o sistema monitora o ambiente de tarefa verificando a passagem do robô móvel pelos marcadores. Foram selecionados quatro instantes distintos (A, B, C e D) durante a realização dessa prova. No quadro A mostra o início do rastreamento, apresentando uma linha azul conforme o robô realiza a navegação. No quadro B o sistema identifica que o robô móvel passou pelo marcador de cor amarela. No quadro C, o sistema reconhece a sobreposição do robô móvel sobre o marcador de cor vermelha. No quadro D o sistema identifica que o robô móvel retornou à marcação de origem e informa que a prova foi concluída.

O MonitoRE identifica as regiões de interesse (marcos artificiais) dos ambientes de tarefas por meio da segmentação e binarização de imagens, estabelecendo máscaras para cada cor identificada no cenário. Em seguida, constantemente o sistema verifica a existência de sobreposição de máscaras, estes parâmetros são comparados com os critérios estabelecidos para o ambiente da tarefa, medindo o desempenho do robô móvel na realização das atividades. 
VII Congresso Brasileiro de Informática na Educação (CBIE 2018)

Anais do XXIX Simpósio Brasileiro de Informática na Educação (SBIE 2018)

\section{Resultados e Discussões}

Esta seção apresenta os resultados obtidos antes (pré-teste), durante (experimentos) e após (pós-teste) a utilização do sistema MonitoRE, avaliando deste as expectativas dos usuários até o impacto desta solução tecnológica no ambiente educacional robótico.

\subsection{Questionário de Pré-Teste}

Este questionário teve como objetivo verificar a necessidade e o interesse das pessoas que atuam na área de robótica pela proposta apresentada por este projeto de pesquisa.

O questionário de pré-teste foi aplicado em uma competição local de robótica, antes do desenvolvimento do sistema MonitoRE, entrevistando cerca de 20 (vinte) pessoas entre alunos e professores roboticistas do Curso Técnico de Informática e Eletrotécnica do IFRO Campus Porto Velho Calama.

Os entrevistados foram questionados sobre as expectativas com a prática da robótica educacional, levantando hipóteses sobre a necessidade de utilizar mecanismos que pudessem automatizar o processo de avaliação das tarefas de robótica educacional, conforme demonstra a Figura 4.

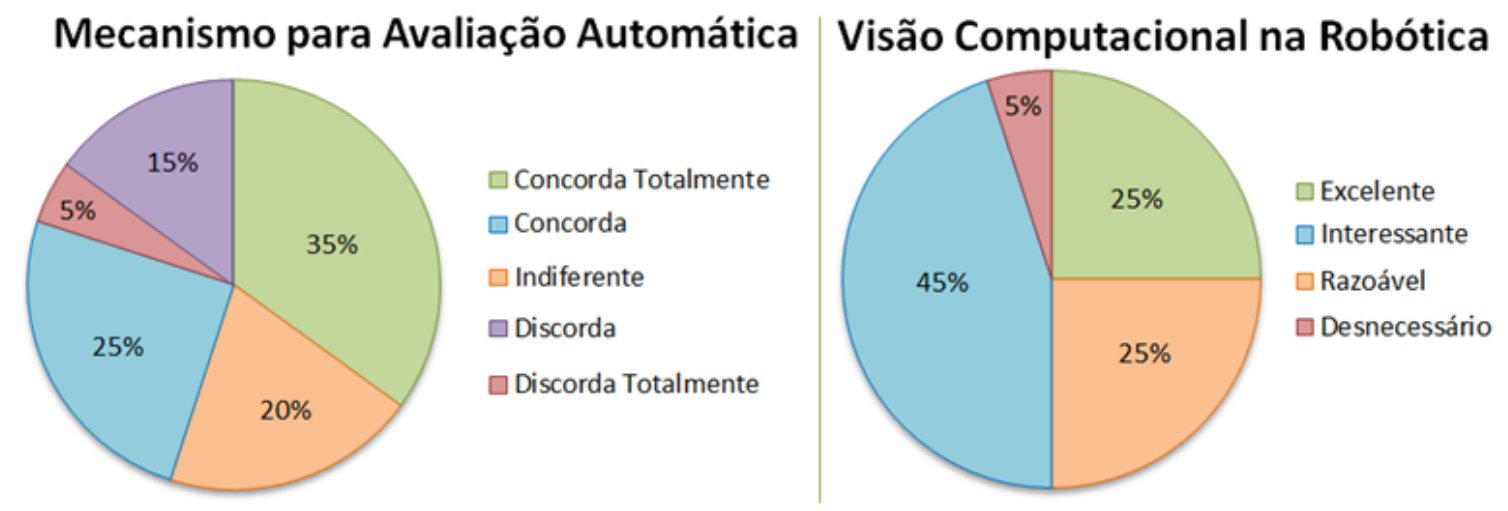

Figura 4. Gráfico sobre a Necessidade de Automação na Robótica.

O primeiro gráfico (esquerda) demonstrou que a maioria das pessoas concordam que existe a necessidade de criar mecanismos para automatizar as avaliações das tarefas com robótica. No entanto, outra parcela de entrevistados relatou não conseguir visualizar como seria esse mecanismo de automação ou de que forma esse mecanismo poderia inferir o desempenho do robô em um ambiente de tarefa.

No segundo gráfico (direita), sobre o que os usuários achariam se em uma próxima competição de robótica existisse um sistema com visão computacional para avaliar o comportamento do robô móvel, foi demonstrado que a maioria dos entrevistados consideraram a ideia interessante e inovadora. Foi relatado ainda que o sistema poderia auxiliar as equipes de robótica e os árbitros na verificação dos lugares, dentro do ambiente de tarefa, em que o robô móvel tenha cometido falha de progresso, permitindo uma análise mais detalhada sobre seu comportamento. 
VII Congresso Brasileiro de Informática na Educação (CBIE 2018)

Anais do XXIX Simpósio Brasileiro de Informática na Educação (SBIE 2018)

\subsection{Testes Experimentais}

Durante o desenvolvimento do sistema e após a conclusão das primeiras versões beta, foi identificada a necessidade de verificar a precisão do processo de visão computacional, quando a luminosidade, para análise dos ambientes de tarefa.

O resultado dos experimentos em cada ambiente de tarefa, colocados em situações de iluminação invariante (sala fechada com iluminação artificial) e variante (ambiente aberto com iluminação natural do dia), são apresentados na Tabela 2.

Tabela 2. Taxa de Erro e Desvio Padrão do Sistema de Visão.

\begin{tabular}{|l|c|c|c|c|}
\hline \multirow{2}{*}{ Ambiente de Tarefa } & \multicolumn{2}{|c|}{ Iluminação Invariante } & \multicolumn{2}{c|}{ Iluminação Variante } \\
\cline { 2 - 5 } & $\begin{array}{c}\text { Taxa de } \\
\text { Erro (\%) }\end{array}$ & $\begin{array}{c}\text { Desvio Padrão } \\
\text { (pixel) }\end{array}$ & $\begin{array}{c}\text { Taxa de Erro } \\
\text { (\%) }\end{array}$ & $\begin{array}{c}\text { Desvio Padrão } \\
\text { (pixel) }\end{array}$ \\
\hline Nível 1 - Marcadores & 0,7 & 5,04 & 18,4 & 117,74 \\
\hline Nível 2 - Resgate & 1,2 & 9,14 & 27,5 & 194,63 \\
\hline Nível 3 - Centro Terra & 1,6 & 13,5 & 34,2 & 279,39 \\
\hline
\end{tabular}

A Taxa de Erro representa a porcentagem de frames em que o robô móvel não foi detectado, afetando o processo de reconhecimento e interpretação do sistema de visão. O Desvio Padrão está associado à variação de pixels existentes na composição das máscaras, utilizadas como parâmetro no sistema de visão. Foi possível observar que a iluminação invariante sobre os ambientes de tarefas permite que o sistema tenha uma precisão acurada, com baixa taxa de erro e com pouca oscilação no desvio padrão, onde os resultados foram promissores.

\subsection{Questionário de Pós-Teste}

Com o sistema devidamente configurado em uma sala com iluminação constante, tentou-se reunir as mesmas pessoas que participaram do questionário de pré-teste. Professores e alunos utilizaram o sistema simulando uma competição de robótica e em seguida responderam ao questionário de pós-teste sobre a experiência com o sistema MonitoRE, conforme demonstra a Figura 7.

\section{Experiência com MonitoRE}

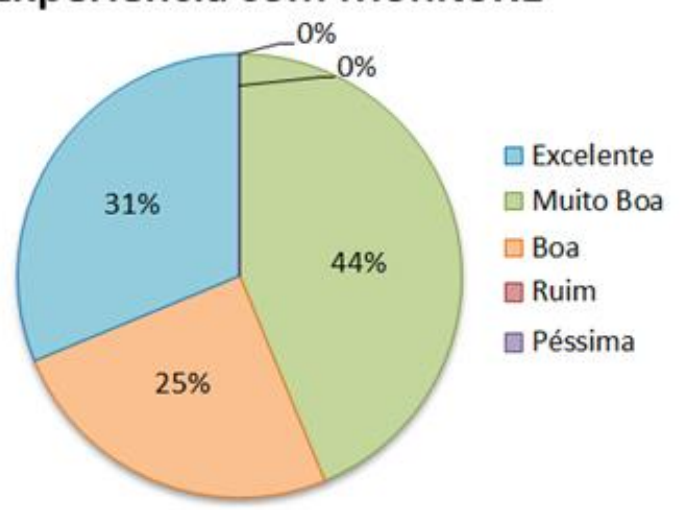

\section{Avaliação pelo MonitoRE}

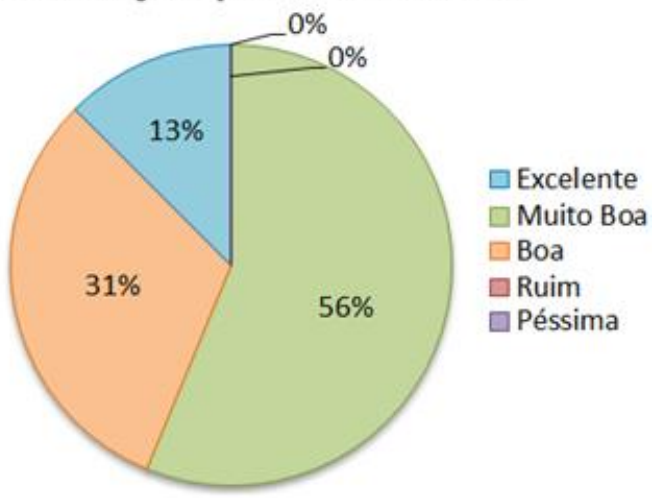

Figura 7. Gráficos sobre Experiência e Avaliação do MonitoRE. 
VII Congresso Brasileiro de Informática na Educação (CBIE 2018)

Anais do XXIX Simpósio Brasileiro de Informática na Educação (SBIE 2018)

O primeiro gráfico (esquerda) mostrou que a maioria dos entrevistados consideram excelente ou muito boa a experiência com o sistema, tendo como índice mais baixo as avaliações tidas como boa. Os professores relataram que o sistema proporciona uma análise visual da trajetória percorrida pelo robô móvel, facilitando o entendimento das decisões tomadas pelo mesmo durante a navegação. Os alunos, ao acompanhar o rastro deixado pelo robô móvel (indicado pelo sistema), melhor compreenderam os motivos que levaram às falhas de progresso.

O segundo gráfico (direita), também demonstrou que a maioria dos entrevistados consideraram muito boa ou excelente a avaliação realizada por meio do sistema. Esses resultados foram obtidos a partir do momento em que a competição e os testes aconteceram em um ambiente controlado, de iluminação constante e com marcadores de cor bem estabelecidos.

\section{Conclusões}

Os resultados dos questionários e dos experimentos realizados, descritos nas seções anteriores, mostraram a aplicabilidade da proposta apresentada. Com base nas informações obtidas foi demonstrado que a utilização do sistema MonitoRE é viável em uma instituição de ensino, desde que ocorra em uma ambiente fechado (como laboratório ou sala de aula).

O sistema possui fragilidades no sentido de depender da iluminação do ambiente, que interfere diretamente tanto nos sensores de cor dos robôs móveis como no processamento de imagens do MonitoRE. Além disso, o sistema depende necessariamente de marcadores baseados em cor, isso significa que o ambiente de tarefa precisa ser configurado com várias cores para que seja analisado pelo MonitoRE, levando em consideração que as cores e formas servem de parâmetro para o sistema.

Contudo, o projeto proposto contribui com uma nova abordagem para a avaliação robótica, onde a solução tecnológica (MonitoRE) e os de ambientes de tarefas são os produtos deste estudo. Tal pesquisa teve como propósito apresentar uma solução inovadora para apoiar o processo de ensino-aprendizagem em ambientes de Robótica Educacional, investigando a motivação dos alunos e o interesse dos professores em atuar sobre um ambiente educacional interativo.

Neste sentido, os trabalhos futuros destinam-se ao aprimoramento do método de localização do robô móvel, buscando alternativas para identificação do mesmo sem a necessidade de utilizar cor. Também há a expectativa de tornar esta solução on-line, permitindo que o professor, tutor ou juiz acesse a competição e acompanhe o desempenho dos robôs à distância.

Por fim, uma versão mobile do MonitoRE poderia tornar o processo de análise ainda mais versátil e flexível. É possível imaginar um aluno que deseja avaliar o desempenho de seu robô móvel apenas apontando a câmera de seu smartphone para o ambiente de tarefa e o sistema imediatamente faria a análise e verificação. Em seguida ele poderia enviar a análise para o professor que, por sua vez, faria as orientações para que o aluno aprimore seus métodos. Desse modo, espera-se que este trabalho colabore para que novas soluções sejam implementadas no contexto da robótica educacional. 
VII Congresso Brasileiro de Informática na Educação (CBIE 2018)

Anais do XXIX Simpósio Brasileiro de Informática na Educação (SBIE 2018)

\section{Referências}

Alimisis, D. (2009) 'Robotic Technologies as Vehicles of New Ways of Thinking About Constructivist Teaching and Learning: The TERECoP Project [Education]', Robotics Automation Magazine, IEEE, 16(3), p. 21,23.

Almeida, T. O., Netto, J. F. M. and Rios, M. L. (2017) 'Remote robotics laboratory as support to teaching programming', Proceedings - Frontiers in Education Conference, FIE, 2017-Octob, pp. 1-6. doi: 10.1109/FIE.2017.8190472.

Benitti, F. B. V. (2012) 'Exploring the educational potential of robotics in schools: A systematic review.', Computers \& Education, pp. 978-988.

Costella, L. Trentin, M. Amarante, V. Teixeira, A. (2017) 'Construção de Ambiente de Ensino de Robótica Remota: Democratizando o desenvolvimento do pensamento computacional em alunos da educação básica', Simpósio Brasileiro de Informática na Educação - SBIE, pp. 354-363.

El-howayek, G. (2016) 'Introducing Computer Engineering Major for First Year Students Using Robotic Projects', Frontiers in Education - FIE, pp. 1-4.

Fiorio, R. Esperandim, R. Silva, F. Varela, P. Leite, M. Reinaldo, F. (2014) 'Uma Experiência Prática da Inserção da Robótica e Seus Beneficios Como Ferramenta Educativa em Escolas Públicas', Simpósio Brasileiro de Informática na Educação.

Hamner, E. Zito, L. Cross, J. Slezak, B. Mellon, S. Harapko, H. Welter, M. (2016) 'Utilizing Engineering to Teach Non-Technical Disciplines: Case Studies of Robotics within Middle School English and Health Classes', Frontiers in Education.

Khanlari, A. (2016) 'Robotics Integration to Create an Authentic Learning Environment in Engineering Education', Frontiers in Education - FIE, pp. 1-4.

Martins, R. Bueno, S. Mirisola, L. Paiva, E. Ferreira, P. (2011) 'Localização em Robótica Terrestre: Fusão Entre Odometria por Múltiplos Encoders e GPS', Simpósio Brasileiro de Automação Inteligente (SBAI), X, pp. 1043-1048.

Oliveira, E. and Araújo, A. L. (2016) 'Pensamento Computacional e Robótica: Um Estudo Sobre Habilidades Desenvolvidas em Oficinas de Robótica Educacional', Simpósio Brasileiro de Informática na Educação - SBIE, (Cbie), pp. 530-539.

Rios, M. (2017) Visão Computacional Aplicada ao Monitoramento de Robôs Móveis em Cenários de Robótica Educacional, Dissertação de Mestrado - UFAM.

Rios, M. L., Custódio, T. and Netto, J. F. M. (2016) 'Definição de Cenários de Robótica Educacional para Análise do Comportamento de Robôs Móveis Utilizando Processamento de Imagem', Workshop de Robótica Educacional - WRE.

Rios, M. L. and Netto, J. F. M. (2016) 'Uma Abordagem Utilizando Visão Computacional para Monitoramento de Robôs Móveis em Ambientes de Tarefas na Robótica Educacional', Simpósio Brasileiro de Informática na Educação - SBIE.

Silva, L. R. (2015) Torneio Juvenil de Robótica: Difundir Desafios Sempre. Viagem ao Centro da Terra: Mais do que um desafio, uma verdadeira viagem a um mundo de novos conhecimentos!, São Paulo. (Accessed: 14 March 2017). 